\title{
CORRELAÇÕES E PARÂMETROS GENÉTICOS DE FAMÍLIAS DE MEIOS-IRMÃOS DO MAMOEIRO DA CULTIVAR RUBI INCAPER 511
}

\author{
Alyce Carla Rodrigues Moitinho' \\ Dayane Gonçalves da Silva ${ }^{2}$ \\ Sarah Ola Moreira ${ }^{3}$ \\ Karin Tesch KuhlCamp ${ }^{4}$ \\ Fabíola Lacerda de Souza Barros ${ }^{5}$
}

Resumo: As correlações e os parâmetros genéticos são estimativas utilizadas para otimizar os trabalhos de melhoramento de plantas. O objetivo desse trabalho foi quantificar tais parâmetros para famílias de meios-irmãos de mamoeiro da cultivar Rubi Incaper 511, aos 8 meses pós semeadura. Foram avaliadas dezoito famílias de meios-irmãos e a cultivar Rubi Incaper 511, em delineamento de blocos ao acaso com cinco repetições e nove plantas por parcela. Foram estimados as variâncias genotípica, fenotípica e ambiental; o coeficiente de determinação genotípico e as correlações fenotípicas, genotípicas e ambientais entre os caracteres: altura da planta $(A P)$, altura de inserção dos primeiros frutos $(A F)$ e diâmetro de caule $(D C)$. As correlações genotípicas foram maiores que a fenotípica, exceto para $A P \times D C$ e houve correlação fenotípica significativa entre as características $A P$ × $A F$ e $A P \times D C$. A variância genotípica foi maior que a ambiental em todas as características avaliadas. Os coeficientes de determinação genotípico indicaram que é possível ter sucesso na seleção das variáveis analisadas.

Palavras-chave: Carica papaya; Melhoramento genético; Herdabilidade; Variâncias; Correlações genéticas.

\footnotetext{
${ }^{1}$ Ciências Biológicas/Faculdade Pitágoras de Linhares, Brasil. E-mail: alycecarla022@hotmail.com.

2 Ciências Biológicas/Faculdade Pitágoras de Linhares, Brasil. E-mail: dayanegonsalves23@hotmail.com.

3 Instituto Capixaba de Pesquisa, Assistência Técnica e Extensão Rural/Centro Regional de Desenvolvimento Rural Centro Serrano, Brasil. E-mail: sarah.moreira@incaper.es.gov.br.

4 Instituto Capixaba de Pesquisa, Assistência Técnica e Extensão Rural/Centro Regional de Desenvolvimento Rural Centro Norte, Brasil. E-mail: fabiola.barros@incaper.es.gov.br.

5 Instituto Capixaba de Pesquisa, Assistência Técnica e Extensão Rural/Centro Regional de Desenvolvimento Rural Centro Norte, Brasil. E-mail: karin.kuhlcamp@incaper.es.gov.br.
} 